\title{
Does Early Resumption of Low-Dose Aspirin After Evacuation of Chronic Subdural Hematoma With Burr-Hole Drainage Lead to Higher Recurrence Rates?
}

\section{Maria Kamenova, MD $\ddagger$ \\ Katharina Lutz, MD§ \\ Sabine Schaedelin, MScף \\ Javier Fandino, MD§ \\ Luigi Mariani, MD * $^{*}$ \\ Jehuda Soleman, MD $\ddagger \S^{*}$}

$¥$ Department of Neurosurgery and ПClinical Trial Unit, University Hospital of Basel, Basel, Switzerland; §Department of Neurosurgery, Kantonsspital Aarau, Aarau, Switzerland

*These authors contributed equally to this work.

\section{Correspondence:}

Jehuda Soleman, MD,

Department of Neurosurgery,

University Hospital of Basel,

Spitalstrasse 21, 4031 Basel,

Switzerland.

E-mail: jehuda.soleman@gmail.com

Received, November 24, 2015.

Accepted, June 3, 2016.

Published Online, August 16, 2016.

Copyright $\odot 2016$ by the

Congress of Neurological Surgeons.

BACKGROUND: Antiplatelet therapy in patients with chronic subdural hematoma (cSDH) presents significant neurosurgical challenges. Given the lack of guidelines regarding perioperative management with antiplatelet therapy, it is difficult to balance the patient's increased cardiovascular risk and prevalence of CSDH.

OBJECTIVE: To better understand the risk and recurrence rates related to resuming low-dose acetylsalicylic acid (ASA) by evaluating our patients' resumption of low-dose ASA at various times after burr-hole drainage of the hematoma.

METHODS: In our retrospective study, 140 consecutive patients taking low-dose ASA undergoing surgical evacuation of $\mathrm{CSDH}$ were included. Data included baseline characteristics and rates of recurrence, morbidity, and mortality. A multivariate logistic regression model analyzed the association between ASA resumption time and recurrence rates.

RESULTS: No statistically significant association was observed between early postoperative resumption of low-dose ASA and recurrence of CSDH (odds ratio, 1.01; 95\% confidence interval, 1.001-1.022; $P=.06$ ). Corresponding odds ratios and risk differences for restarting ASA treatment on postoperative days $1,7,14,21,28,35$, or 42 were estimated at 1.53 and $5.9 \%, 1.42$ and $5.1 \%, 1.33$ and $4.1 \%, 1.23$ and $3.2 \%, 1.15$ and $2.2 \%$, 1.07 and $1.1 \%$, and 1.01 and $0.2 \%$, respectively $(P>.05)$. Cardiovascular event rates, surgical morbidity, and mortality did not significantly differ between patients with or without ASA therapy.

CONCLUSION: Given the few published studies regarding ASA use in cranial neurosurgery, our findings elucidate one issue, showing comparable recurrence rates with early or late resumption of low-dose ASA after burr-hole evacuation of cSDH.

KEY WORDS: Burr-hole drainage, Chronic subdural hematoma, Low-dose acetylsalicylic acid, Recurrence rate

Neurosurgery 79:715-721, 2016

DOI: $10.1227 /$ NEU. 0000000000001393

www.neurosurgery-online.com

A cetylsalicylic acid (ASA) is a drug widely prescribed for the primary and secondary prevention of coronary artery disease (CAD). ${ }^{1,2}$ ASA has been shown to reduce the risk of cardiovascular death or subsequent attacks in patients with previous myocardial infarction, unstable angina, stroke, or transient ischemic

ABBREVIATIONS: ASA, acetylsalicylic acid; CAD, coronary artery disease; $\mathrm{Cl}$, confidence interval; cSDH, chronic subdural hematoma; GCS, Glasgow Coma Scale; $\mathbf{m R S}$, modified Rankin Scale; OR, odds ratio; $\mathbf{R D}$, risk difference attacks. ${ }^{3,4}$ Nearly $40 \%$ of the patients who undergo noncardiac surgery worldwide have or are at risk of CAD; of these, $4 \% / y$ develop a major intraoperative cardiovascular complication, including cardiac death, nonfatal myocardial infarction, and cardiac arrest. ${ }^{5,6}$ In-hospital mortality caused by perioperative myocardial infarction ranges from $15 \%$ to $25 \% .^{6-8}$

The incidence of chronic subdural hematoma $(\mathrm{CSDH})$ is estimated at 1.7 to 18 per 100000 people and rises to 58 per 100000 in people $>65$ years of age. ' Its significantly higher prevalence among patients $>65$ years of age $(69 \%)$ vs younger patients (31\%) is partially explained by $41 \%$ of the 
patients taking platelet aggregation inhibitors or oral anticoagulants. ${ }^{10}$ Antiplatelet therapy in patients with $\mathrm{cSDH}$ presents a significant neurosurgical challenge. Although patients seem to be at greater risk for $\mathrm{cSDH}$ while taking these medications, it remains unclear how antiplatelet therapy affects recurrence rates.,11-13 Despite no definitive evidence for the preoperative discontinuation of antiplatelet therapy, most surgeons prefer to discontinue or to revert antiplatelet therapy before surgery. ${ }^{14}$ Once discontinued, the optimal timing for the postoperative resumption of antiplatelet therapy is not defined. ${ }^{15}$ Of course, ASA is typically resumed as soon as possible in patients at risk for major perioperative cardiovascular complication, even though its early postoperative resumption might lead to higher cSDH recurrence rates.

In balancing the increased cardiovascular risk with increasing prevalence of $\mathrm{cSDH}$, a lack of guidelines and recommendations persists regarding the perioperative management of patients with antiplatelet therapy. In this study of patients who underwent burrhole evacuation of $\mathrm{cSDH}$, we examine recurrence rates, morbidity, and mortality related to the timing of resuming low-dose ASA therapy.

\section{METHODS}

In this retrospective review of 750 consecutive patients who underwent evacuation of cSDH by burr-hole drainage (January 2009-June 2014), there were 391 patients from the University Hospital of Basel and 359 patients from the Kantonsspital of Aarau. Of these, 144 patients (19.2\%), including 38 women $(26.3 \%)$ and 106 men $(73.7 \%)$, were taking lowdose ASA (aspirin cardio $100 \mathrm{mg}$ once daily) before surgery; 4 patients $(2.77 \%)$ were then excluded because of missing information on ASA use. Medical records and radiological findings were reviewed for 140 patients, including clinical variables such as age, sex, side of the $\mathrm{cSDH}$, comorbidities, presenting symptoms, and concomitant antiplatelet therapy (Tables 1 and 2). The study protocol was approved by the local ethics committee (EKNZ, Basel, Switzerland). For this retrospective study, patient consent was not sought because the administrative burden would be disproportionately large and therefore consent is not necessary according to local ethics guidelines.

The diagnosis of all patients was symptomatic, 1-sided, or bilateral $\mathrm{cSDH}$ confirmed by computed tomography or magnetic resonance imaging. All patients were treated surgically with burr-hole drainage, irrigation of the hematoma, and insertion of a drain without suction for 48 hours postoperatively. Indication for surgery was a hematoma $>1 \mathrm{~cm}$ leading to neurological symptoms. Patients who presented with an acute subdural hematoma and those who underwent a craniotomy were excluded from the study.

In 32 patients $(22.9 \%)$ presenting with minor symptoms (headache, gait disturbance, etc), ASA was discontinued at least 5 days before elective surgery. The other 108 patients $(77.1 \%)$ underwent emergency burr-hole evacuation under the effect of ASA treatment; 80 patients $(74.1 \%)$ had taken ASA the day of surgery, whereas $12(11.1 \%), 8(7.4 \%), 3(2.8 \%)$, and $5(4.6 \%)$ patients had discontinued ASA treatment 1, 2, 3, and 4 days before the operation, respectively. The decision on when to resume ASA treatment postoperatively was based on the surgeons' personal experience and considerations about its initial indications for use. In 32 patients (22.9\%), the indication for ASA treatment was not confirmed postoperatively, and the treatment was stopped.

\begin{tabular}{|c|c|c|c|c|}
\hline & \multicolumn{4}{|c|}{ Recurrent cSDH, n } \\
\hline & $\begin{array}{c}\text { Total } \\
(n=140)\end{array}$ & $\begin{array}{c}\text { No } \\
(n=121)\end{array}$ & $\begin{array}{c}\text { Yes } \\
(n=19)\end{array}$ & $\begin{array}{c}P \\
\text { Value }\end{array}$ \\
\hline$M / F$ & $102 / 38$ & $85 / 36$ & $17 / 2$ & .10 \\
\hline Location, left/right/bilateral & $60 / 50 / 30$ & $49 / 46 / 26$ & $11 / 4 / 4$ & .31 \\
\hline $\begin{array}{l}\text { ASA discontinued } \\
\text { preoperatively, }>5 \mathrm{~d} /<5 \mathrm{~d}\end{array}$ & $104 / 32$ & $90 / 27$ & $14 / 5$ & .77 \\
\hline \multicolumn{5}{|l|}{ Secondary diagnosis } \\
\hline $\begin{array}{l}\text { Concomitant blood } \\
\text { thinners }\end{array}$ & 20 & 15 & 5 & .15 \\
\hline CAD & 76 & 63 & 13 & .22 \\
\hline Coronary stent & 26 & 20 & 6 & .12 \\
\hline Arterial hypertension & 102 & 88 & 14 & $>.99$ \\
\hline Coronary bypass & 7 & 7 & 0 & .60 \\
\hline Diabetes mellitus & 20 & 17 & 3 & .74 \\
\hline $\begin{array}{l}\text { Transient ischemic attack/ } \\
\text { cerebrovascular insult }\end{array}$ & 18 & 16 & 2 & $>.99$ \\
\hline $\begin{array}{l}\text { Peripheral artery occlusive } \\
\text { disease }\end{array}$ & 8 & 7 & 1 & .35 \\
\hline Carotid stent & 2 & 1 & 1 & .25 \\
\hline Atrial fibrillation & 16 & 13 & 3 & .46 \\
\hline Hypercholesterolemia & 33 & 31 & 2 & .24 \\
\hline
\end{tabular}

${ }^{a} \mathrm{ASA}$, acetylsalicylic acid; $\mathrm{CAD}$, coronary artery disease; $\mathrm{CSDH}$, chronic subdural hematoma.

The primary end point of the study was recurrence that required revision surgery owing to clinical symptoms. The secondary end points were major cardiovascular events (eg, ST-segment-elevation myocardial infarction, defined as ST-segment elevation on electrocardiogram of $>1$ $\mathrm{mm}$ in at least 1 derivation with or without clinical symptoms of myocardial infarction, and non-ST-segment elevation myocardial

TABLE 2. Continuous Variables ${ }^{a}$

\begin{tabular}{|c|c|c|c|c|}
\hline & \multicolumn{4}{|c|}{ Recurrent CSDH } \\
\hline & $\begin{array}{c}\text { Total } \\
(n=140), \\
\text { Mean } \pm \text { SD }\end{array}$ & $\begin{array}{c}\text { No }(n=121) \\
\text { Mean } \pm \text { SD }\end{array}$ & $\begin{array}{l}\text { Yes }(n=19) \\
\text { Mean } \pm \text { SD }\end{array}$ & $\begin{array}{c}P \\
\text { Value }\end{array}$ \\
\hline Age, y & $77.3 \pm 8.3$ & $77.4 \pm 8.4$ & $76.7 \pm 7.4$ & .73 \\
\hline $\begin{array}{l}\text { Operation } \\
\text { time, min }\end{array}$ & $59.8 \pm 26.9$ & $60.3 \pm 27.8$ & $55.5 \pm 20.3$ & .79 \\
\hline $\begin{array}{l}\text { Hospitalization } \\
\text { time, } d\end{array}$ & $9.8 \pm 5.6$ & $9.4 \pm 5.2$ & $12.8 \pm 7.1$ & $.03^{b}$ \\
\hline $\begin{array}{l}\text { Preoperative } \\
\text { GCS score }\end{array}$ & $13.8 \pm 2.5$ & $13.9 \pm 2.4$ & $13.5 \pm 3.1$ & .74 \\
\hline $\begin{array}{l}\text { Postoperative } \\
\text { GCS score }\end{array}$ & $14.6 \pm 1.5$ & $14.7 \pm 1.3$ & $14.0 \pm 2.2$ & .07 \\
\hline $\begin{array}{l}\text { Postoperative } \\
\text { mRS score }\end{array}$ & $0.9 \pm 1.3$ & $0.78 \pm 1.2$ & $1.78 \pm 1.5$ & $.03^{b}$ \\
\hline
\end{tabular}

${ }^{a} \mathrm{CSDH}$, chronic subdural hematoma; GCS, Glasgow Coma scale; mRS, modified Rankin Scale.

${ }^{b}$ Significant. 
infarction, defined as troponin elevation of at least $7 \mathrm{ng} / \mathrm{L}$ within 3-4 hours with or without clinical symptoms of myocardial infarction without ST-segment elevation on electrocardiogram), cerebrovascular insult, morbidity, and mortality.

All 140 patients were followed up clinically (mean, 43.5 days postoperatively); of these, 112 patients $(80 \%)$ had a postoperative computed tomography scan (mean, 38.2 days).

\section{Statistical Analysis}

The association between ASA resumption (in days) and recurrence rate was analyzed with a logistic regression model. Continuous variables were the number of days from surgery to ASA resumption. The association was assessed by change in odds ratio (OR) by days until ASA use resumed. Confidence intervals (CIs) were calculated as previously described. ${ }^{16}$ Additionally, the corresponding $\mathrm{OR}$ and risk difference (RD) for resuming ASA treatment were calculated for immediately after surgery vs days $1,7,14,21,28,35$, and 42 . Possible confounders assessed by a supportive multivariate logistic regression analysis used the following covariables: age, sex, preoperative and postoperative Glasgow Coma Scale (GCS) scores, postoperative modified Rankin Scale (mRS) score (6-point scale measuring the extent of disability and dependence in daily activities, ranging from $0=$ no symptoms to $6=$ death), days ASA treatment was discontinued before surgery, and concomitant blood thinners (eg, clopidogrel, vitamin $\mathrm{K}$ antagonists). Calculations were then repeated, excluding all 32 patients instructed not to resume ASA treatment postoperatively because of their potential to fundamentally differ in recurrence rates from those who resumed ASA.

Planning of methodology and statistical analyses was completed with cooperation from a statistician (S.S.) of the Clinical Trial Unit of the University Hospital of Basel. Statistical calculations were done with $\mathrm{R}$ (Comprehensive R Archive Network, R Foundation for Statistical Computing, Vienna, Austria). Categorical data were analyzed with the Fisher exact test, and continuous data were analyzed with the MannWhitney $U$ test. A value of $P<.05$ was considered significant.

\section{RESULTS}

\section{Effect of ASA Resumption on the Recurrence Rate of CSDH}

cSDH recurrences developed in 18 of the 108 patients $(16.7 \%)$ who resumed low-dose ASA postoperatively and in 1 of 32 patients (3.1\%) who never resumed ASA $(P=.07)$. No significant associations were seen between the time of resuming ASA treatment postoperatively and recurrence rate of cSDH $(\mathrm{OR}$, 1.01; 95\% CI, 1.022-1.001; $P=.06$ ).

The distribution of recurrent events by recommencement of ASA is shown in Table 3. Considering all 140 patients, the risk of recurrence after resuming ASA treatment earlier was estimated at $1 \% / w k$. The calculated $\mathrm{OR}$ and $\mathrm{RD}$ for recurrent $\mathrm{cSDH}$ when ASA treatment was restarted on postoperative day 1, 7, 14, 21, 28, 35 , or 42 were estimated at 1.53 and $5.9 \%, 1.42$ and $5.1 \%, 1.33$ and $4.1 \%, 1.23$ and $3.2 \%, 1.15$ and $2.2 \%, 1.07$ and $1.1 \%$, and 1.01 and $0.2 \%$, respectively $(P>.05$; Table 4$)$. In the subanalysis that excluded the 32 patients who never resumed ASA use postoperatively, no significant association between ASA resumption time and recurrent events was found (OR, 1.004; 95\% CI, 0.985-

\begin{tabular}{|lcc|}
\hline \multicolumn{2}{|c|}{ TABLE 3. Resumption of ASA Treatment and Recurrent Events ${ }^{a}$} \\
\hline ASA Treatment & Patients, $\mathbf{n}$ & $\begin{array}{c}\text { Recurrent } \\
\text { Events, } \mathbf{n}(\%)\end{array}$ \\
\hline ASA not discontinued $(<5 \mathrm{~d})$ & 9 & $2(22.2)$ \\
ASA discontinued & & $2(10.0)$ \\
5-7 d & 20 & $4(23.5)$ \\
8-14 d & 17 & $2(16.7)$ \\
15-28 d & 12 & $6(25.0)$ \\
29-42 d & 24 & $2(7.7)$ \\
AS-90 d & 26 & $18(16.7)^{b}$ \\
ASA treatment resumed & 108 & $1(3.1)^{b}$ \\
\hline
\end{tabular}

${ }^{a}$ ASA, acetylsalicylic acid.

${ }^{b} P=.07$.

1.022; $P=.68$ ); however, once ASA treatment was restarted earlier, recurrence rates dropped to approximately 0.4\%/wk. Among patients who eventually resumed ASA treatment, the calculated $\mathrm{OR}$ and $\mathrm{RD}$ of experiencing a recurrent $\mathrm{cSDH}$ when restarting treatment on the postoperative day $1,7,14,21,28,35$, or 42 was estimated at 1.18 and $2.4 \%, 1.15$ and $2.0 \%, 1.12$ and $1.6 \%, 1.08$ and $1.2 \%, 1.06$ and $0.82 \%, 1.03$ and $0.4 \%$, and 1.01 and $0.1 \%$, respectively $(P>.05$; Table 4$)$.

\section{Analysis of Potential Confounders}

After adjustment for potential confounders, we again found no association between ASA resumption time and increased recurrence rate of cSDH (Table 5). Low postoperative GCS score (OR, 1.28; 95\% CI, 0.99-1.66; $P=.04)$ and worse postoperative $\mathrm{mRS}$ score (OR, 1.59; 95\% CI, 1.14-2.23; $P=.006$ ) were found to be independent risk factors significantly increasing the recurrence of cSDH (Table 5). In multivariate analysis excluding patients who never resumed ASA postoperatively, timing of ASA treatment resumption was not associated with higher recurrence rates. However, low postoperative GCS score (OR, 1.43; 95\% CI, $1.02-2.13 ; P=.04$ ) and worse postoperative $\mathrm{mRS}$ score (OR, $1.58 ; 95 \% \mathrm{CI}, 1.10-2.31 ; P=.02)$ remained independent risk factors that significantly increased the recurrence of $\mathrm{cSDH}$. Interestingly, the days of ASA discontinuation preoperatively had no impact on recurrence rates. Therefore, we concluded that evacuation of hemorrhage in a patient while taking ASA did not significantly increase cSDH recurrence rates in our patients.

\section{Major Cardiovascular Events}

Postoperative cardiovascular events occurred in 10 patients (7.1\%), with no significant difference between 9 patients $(6.9 \%)$ who continued or 1 patient $(11.1 \%)$ who discontinued ASA treatment $(P=.21$; Table 6$)$. Similarly, the individual rates of myocardial infarction and other cardiovascular events (eg, peripheral artery occlusion, pulmonary embolism) were not significantly different between patients under continuous or 
TABLE 4. Risk of Recurrence and Days of Postoperative ASA Resumption ${ }^{a}$

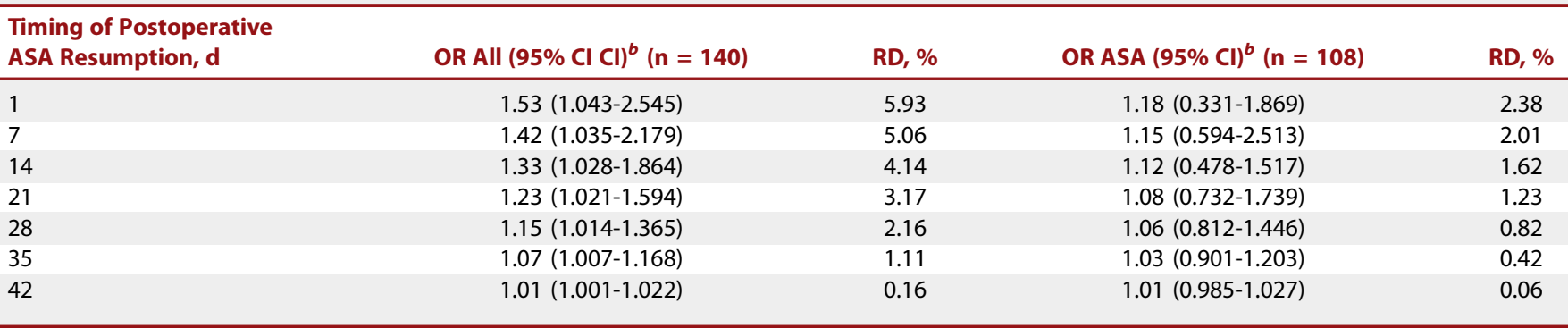

${ }^{a}$ ASA, acetylsalicylic acid; $\mathrm{Cl}$, confidence interval; OR All, odds ratio of recurrence when resuming ASA treatment in all patients; OR ASA, odds ratio of recurrence only in patients in whom ASA treatment was eventually resumed; RD, risk difference.

${ }^{b}$ All values are estimated calculations with a nonsignificant $P$ value of .06 .

discontinued ASA treatment (Table 6). All cardiovascular events occurred after postoperative day 7 (range, 8-34 days).

\section{Surgical Morbidity}

Surgical morbidity rates of $11.1 \%(\mathrm{n}=1)$ in patients with continuous ASA treatment and $14.5 \%(\mathrm{n}=19)$ in patients with discontinued ASA treatment were not statistically different $(P>$ .99). Surgical morbidities were meningitis in 1 patient, epileptic seizures in 7 patients, wound infection in 5 patients ( 2 underwent surgery, 3 were treated conservatively with antibiotics), intraparenchymal hemorrhage in 4 patients, and subdural empyema requiring revision surgery in 4 patients.

\section{Mortality}

One patient (11.1\%) who continued ASA use developed postoperative meningitis and intraparenchymal hemorrhage requiring recraniotomy and died of acute renal failure. Mortality rate was $3.1 \%$ in the 4 patients who discontinued ASA; causes of death were subdural empyema requiring revision surgery, pulmonary embolism with exacerbated pulmonary infection, postoperative intraparenchymal hemorrhage that required decompressive hemicraniectomy, and sepsis with cardiopulmonary decompensation. Mortality rates did not significantly differ between patients who continued or discontinued ASA treatment $(P=.26 ;$ Table 6$)$.

\section{DISCUSSION}

Given the sparse studies, mostly case reports, investigating the effect of ASA therapy in cranial neurosurgery, the issue of whether low-dose ASA should be discontinued after elective intracranial surgery remains. Aiming to examine its effects in our 140 patients who underwent evacuation for $\mathrm{cSDH}$, we found no significant association between timing of resuming low-dose ASA use postoperatively and recurrent hemorrhage. Specifically, the RD for recurrence was $1 \% / \mathrm{wk}$ for resuming ASA in all patients and $0.4 \%$ / wk when the 32 patients who never resumed ASA were excluded. We identified a trend toward lower recurrence rates in patients who never resumed low-dose ASA postoperatively $(P=.07)$. Therefore, if no definitive guideline-based primary or secondary prevention indication exists, ASA therapy should not be resumed. We found no significant association between discontinued ASA

TABLE 5. Multivariate Analysis of Confounders ${ }^{a}$

\begin{tabular}{|c|c|c|c|c|}
\hline Confounder & OR $(95 \% \mathrm{Cl})$ & $P$ Value & \multicolumn{2}{|c|}{ Effect on the Main Analysis ${ }^{b}$} \\
\hline Age & $1.01(0.94-1.06)$ & .8 & $1.01(1.00-1.03)$ & .06 \\
\hline Concomitant blood thinner therapy & $1.90(0.54-6.12)$ & .29 & $1.009(1.00-1.02)$ & .09 \\
\hline Discontinuation of ASA before surgery, $d$ & $1.05(0.97-1.25)$ & .40 & $1.009(1.00-1.02)$ & .06 \\
\hline Preoperative GCS score & $1.06(0.87-1.25)$ & .49 & $1.01(1.00-1.03)$ & .06 \\
\hline
\end{tabular}

${ }^{a}$ ASA, acetylsalicylic acid; $\mathrm{Cl}$, confidence interval; GCS, Glasgow Coma scale; mRS, modified Rankin Scale; OR, odds ratio.

${ }^{b}$ Effect of the cofounders on the OR of recurrence rate if ASA is resumed earlier.

'Significant. 
TABLE 6. Cardiovascular Events and Mortality ${ }^{a}$

\begin{tabular}{|c|c|c|c|c|}
\hline & \multirow[b]{2}{*}{ Total $(n=140)$} & \multicolumn{2}{|c|}{ ASA Therapy } & \multirow[b]{2}{*}{$P$ Value } \\
\hline & & Discontinued $^{b}(n=131)$ & Resumed $^{c}(n=9)$ & \\
\hline Myocardial infarction & 4 & 3 & 1 & .24 \\
\hline Non-ST-segment-elevation myocardial infarction & 3 & 2 & 1 & \\
\hline Other cardiovascular events & 6 & 6 & 0 & $>.99$ \\
\hline Occlusion of femoral artery & 1 & 1 & $\ldots$ & \\
\hline All cardiovascular events & 10 & 9 & 1 & .5 \\
\hline Mortality & 5 & 4 & 1 & .21 \\
\hline
\end{tabular}

${ }^{a}$ ASA, acetylsalicylic acid.

${ }^{b}$ ASA resumed $>5$ days postoperatively.

${ }^{c}$ ASA resumed $<5$ days postoperatively.

use and rates of cardiovascular events or mortality. However, in $90 \%$ of the 10 patients $(7.1 \%)$ having a postoperative cardiovascular event and in $80 \%$ of the 5 patients who died $(3.6 \%)$, ASA was not being taken. Surgical morbidity was not significantly influenced by resumption of ASA treatment. Of 20 patients (14.3\%) who developed a surgical complication, only 1 patient (5\%) was taking ASA treatment.

\section{ASA Therapy and Intracranial Surgery}

Studies investigating the effect of ASA in cranial neurosurgery are sparse and mostly based on case reports. ${ }^{14}$ In 1979, Merriman et $\mathrm{al}^{17}$ first reported on 2 neurosurgical patients who developed postoperative hematomas allegedly secondary to ASA-induced platelet defect. Stroobandt et al $^{18}$ identified ASA as a possible predisposing factor for $\mathrm{cSDH}$ in $16 \%$ of 132 patients with subdural hematoma. The question of whether preoperative lowdose ASA should be discontinued before elective intracranial surgery has never been satisfactorily answered. ${ }^{14}$ In a mail survey of neurosurgeons' opinions on perioperative use of antiplatelet agents, Korinth ${ }^{14}$ reported that $19.6 \%$ of the respondents had no policy or guidelines concerning this issue at their clinic. Furthermore, $77.5 \%$ of the neurosurgeons felt that patients undergoing ASA therapy were at a higher bleeding risk perioperatively, and $12.9 \%$ noted a personal experience with bleeding complications in patients taking low-dose ASA. To the

TABLE 7. Implication of Our Results for Daily Practice ${ }^{a}$

\begin{tabular}{|c|c|c|}
\hline Patient Type & Recommendation & Rationale \\
\hline $\begin{array}{l}\text { No indication for primary or } \\
\text { secondary CAD prevention }\end{array}$ & $\begin{array}{l}\text { ASA treatment should not be resumed } \\
\text { postoperatively. }\end{array}$ & $\begin{array}{l}\text { Our results show a trend toward lower recurrence rates in } \\
\text { patients who never resumed ASA treatment postoperatively. }\end{array}$ \\
\hline Primary CAD prevention & $\begin{array}{l}\text { Discontinuation of ASA treatment } \\
\text { during the perioperative period of } \\
\text { CSDH (eg } 4-6 \text { wk) might be justified. }\end{array}$ & $\begin{array}{l}\text { ASA does not seem to affect cardiovascular mortality. }{ }^{7,20} \\
\text { Therefore the risk for cardiovascular events does not exceed } \\
\text { the risk of having a recurrent cSDH. }\end{array}$ \\
\hline \multirow[t]{3}{*}{ Secondary CAD prevention } & $\begin{array}{l}\text { Discontinuation of ASA treatment for } 7- \\
10 \mathrm{~d} \text {, thereafter resumption of ASA } \\
\text { treatment. }\end{array}$ & $\begin{array}{l}\text { The benefit of ASA treatment for secondary CAD prevention is } \\
\text { well known. }\end{array}$ \\
\hline & & $\begin{array}{l}\text { The estimated OR and RD for a recurrent event, depending on } \\
\text { the timing of resuming ASA treatment provided in Table 4, can } \\
\text { become essential aids in this decision making. }\end{array}$ \\
\hline & $\begin{array}{l}\text { Caution should be taken in patients } \\
\text { with low postoperative GCS score or } \\
\text { high postoperative } \mathrm{mRS} \text { score. }\end{array}$ & $\begin{array}{l}\text { In our study, low postoperative GCS score and worse } \\
\text { postoperative mRS score were found to be independent risk } \\
\text { factors for the recurrence of CSDH. }\end{array}$ \\
\hline
\end{tabular}

${ }^{a}$ ASA, acetylsalicylic acid; CAD, coronary artery disease; cSDH, chronic subdural hematoma; GCS, Glasgow Coma scale; mRS, modified Rankin Scale. 
best of our knowledge, no previous studies have evaluated cSDH recurrence rates in patients taking antiplatelet therapy and related to timing of resuming ASA postoperatively.

\section{The Implication of Our Results for Daily Practice}

Our results showed a trend toward lower $\mathrm{CSDH}$ recurrence rates in patients who never resumed low-dose ASA postoperatively $(P=.07)$. Given this trend and other published findings, we recommend that, before ASA treatment is resumed after surgical evacuation of cSDH, its indication should be evaluated. If no definitive, guideline-based primary or secondary prevention indication exists, ASA should not be resumed (Table 7).

In the setting of primary CAD prophylaxis, ASA does not seem to affect perioperative cardiovascular mortality. ${ }^{7,19}$ Our data show a trend toward higher recurrence rates of $\mathrm{cSDH}$ in patients in whom ASA therapy was resumed at any time. Therefore, in patients taking low-dose ASA for primary CAD, its discontinuation for 4 to 6 weeks postoperatively might be justified (Table 7).

The benefits of ASA treatment for secondary CAD prevention are well known. ${ }^{7,19}$ Our results show no significant increase in recurrence rates with earlier resumption of ASA. Considering our results and other published data, in patients under ASA treatment for secondary $\mathrm{CAD}$ prophylaxis, withdrawal of ASA treatment for 7 to 10 days might be justified. However, these decisions should be individualized, taking into account the specific cardiovascular risk profile of each patient. We believe that the estimated OR and RD for a recurrent event, depending on the timing of resuming ASA treatment (Table 4), can become essential aids in this decision making.

In our cohort, $84.2 \%$ of the recurrences $(n=16)$ occurred before postoperative day 42 . Up to this time point, we estimated a continuous increase $(\approx 1 \% / \mathrm{wk})$ when resuming ASA therapy earlier. However, after day 42, the risk of recurrence, even if ASA therapy is resumed, does not continue to increase in a linear fashion. Rather, the risk for recurrence after day 42 seems low; therefore, ASA treatment should be reinstated, at the latest, by 6 weeks postoperatively.

The overall rate of major postoperative thrombotic events in our cohort was lower than expected. A possible explanation might be that in patients with a strong indication for ASA use (eg, history of myocardial infarction), treatment was resumed earlier or, alternatively, not discontinued at all, and thus our patients received adequate preventive treatment during the perioperative period. Of note, in 108 patients (77\%), the fact that ASA was not discontinued until the day of the operation might also explain the low percentage of cardiovascular events. Interestingly, no association with lower recurrence rates in patients in whom ASA was discontinued 5 days preoperatively was seen. These results are slightly surprising because after ASA therapy is discontinued, a period of 5 to 6 days is required to replace approximately $50 \%$ of the circulating platelets $(10 \% / 24 \mathrm{~h}){ }^{20,21}$ Therefore, these patients may have still been under partial antithrombotic effect during the operation and in the early perioperative period. Moreover, if postoperative ASA therapy were continued early (eg, within 5 days), the patient might have even been under continuous ASA treatment effect. In contrast, studies have also shown that in line with the ASA withdrawal syndrome, half of the patients demonstrate normal platelet function at 72 hours, and $80 \%$ normalized at 96 hours from the last aspirin dose. ${ }^{7,22}$

\section{Study Limitations}

This retrospective study is subject to all the limitations of data collection inherent in such works. ASA resumption was based on surgeons' decision making, which obviously causes a selection bias. However, this bias is almost unavoidable because the indication for ASA and the patient's condition will always play a role in the decision making for when to restart ASA treatment postoperatively. The incidence of thrombotic events under discontinued ASA medication in our cohort was slightly lower than reported in the literature $(6.9 \%$ vs $10.1 \%)$. This might be due to the fact that patients were not screened for thrombotic events. Therefore, some cardiovascular events such as an asymptomatic myocardial infarction/ischemia or myocardial injury after noncardiac surgery might have been missed.

\section{CONCLUSION}

In patients undergoing burr-hole drainage for $\mathrm{CSDH}$, early and late resumption of low-dose ASA therapy showed comparable recurrence rates. In face of the risk of cardiovascular events, in patients treated for secondary CAD, resumption of ASA treatment after 7 to 10 days may be warranted. Further prospective studies with a larger cohort are needed to confirm our results.

\section{Disclosure}

The authors have no personal, financial, or institutional interest in any of the drugs, materials, or devices described in this article.

\section{REFERENCES}

1. Hall R, Mazer CD. Antiplatelet drugs: a review of their pharmacology and management in the perioperative period. Anesth Analg. 2011;112(2):292-318.

2. Mollmann H, Nef HM, Hamm CW. Clinical pharmacology: antiplatelet therapy during surgery. Heart. 2010;96(12):986-991.

3. Hennekens $\mathrm{CH}$, Dyken ML, Fuster V. Aspirin as a therapeutic agent in cardiovascular disease: a statement for healthcare professionals from the American Heart Association. Circulation. 1997;96(8):2751-2753.

4. Nielsen JD, Holm-Nielsen A, Jespersen J, Vinther CC, Settgast IW, Gram J. The effect of low-dose acetylsalicylic acid on bleeding after transurethral prostatectomy: a prospective, randomized, double-blind, placebo-controlled study. Scand J Urol Nephrol. 2000;34(3):194-198.

5. Mangano DT. Perioperative cardiac morbidity. Anesthesiology. 1990;72(1):153-184.

6. Oscarsson A, Gupta A, Fredrikson M, et al. To continue or discontinue aspirin in the perioperative period: a randomized, controlled clinical trial. BrJ Anaesth. 2010; 104(3):305-312.

7. Gerstein NS, Schulman PM, Gerstein WH, Petersen TR, Tawil I. Should more patients continue aspirin therapy perioperatively? Clinical impact of aspirin withdrawal syndrome. Ann Surg. 2012;255(5):811-819.

8. Kumar R, McKinney WP, Raj G, et al. Adverse cardiac events after surgery: assessing risk in a veteran population. J Gen Intern Med. 2001;16(8):507-518.

9. Ducruet AF, Grobelny BT, Zacharia BE, et al. The surgical management of chronic subdural hematoma. Neurosurg Rev. 2012;35(2):155-169; discussion 169.

10. Baechli H, Nordmann A, Bucher HC, Gratzl O. Demographics and prevalent risk factors of chronic subdural haematoma: results of a large single-center cohort study. Neurosurg Rev. 2004;27(4):263-266. 
11. Forster MT, Mathe AK, Senft C, Scharrer I, Seifert V, Gerlach R. The influence of preoperative anticoagulation on outcome and quality of life after surgical treatment of chronic subdural hematoma. J Clin Neurosci. 2010;17(8):975-979.

12. Lindvall P, Koskinen LO. Anticoagulants and antiplatelet agents and the risk of development and recurrence of chronic subdural haematomas. $J$ Clin Neurosci. 2009;16(10):1287-1290.

13. Rust T, Kiemer N, Erasmus A. Chronic subdural haematomas and anticoagulation or anti-thrombotic therapy. J Clin Neurosci. 2006;13(8):823-827.

14. Korinth MC. Low-dose aspirin before intracranial surgery: results of a survey among neurosurgeons in Germany. Acta Neurochir (Wien). 2006;148(11):11891196;249-281; discussion 1196.

15. Soleman J, Taussky P, Fandino J, Muroi C. Evidence-based treatment of chronic subdural hematoma. In: Sadaka DF, ed. Traumatic Brain Injury. Rijeka, Croatia: InTech; 2014.

16. Venables WN, Ripely BD. Modern Applied Statistics. 4th ed. New York, NY: Springen; 2002.

17. Merriman E, Bell W, Long DM. Surgical postoperative bleeding associated with aspirin ingestion: report of two cases. J Neurosurg. 1979;50(5):682-684.

18. Stroobandt G, Fransen P, Thauvoy C, Menard E. Pathogenetic factors in chronic subdural haematoma and causes of recurrence after drainage. Acta Neurochir (Wien). 1995;137(1-2):6-14.

19. Korte W, Cattaneo M, Chassot PG, et al. Peri-operative management of antiplatelet therapy in patients with coronary artery disease: joint position paper by members of the working group on Perioperative Haemostasis of the Society on Thrombosis and Haemostasis Research (GTH), the Working Group on Perioperative Coagulation of the Austrian Society for Anesthesiology, Resuscitation and Intensive Care (OGARI) and the Working Group Thrombosis of the European Society for Cardiology (ESC). Thromb Haemost. 2011;105(5):743-749.

20. Doutremepuich C, de Seze O, Le Roy D, Lalanne MC, Anne MC. Aspirin at very ultra low dosage in healthy volunteers: effects on bleeding time, platelet aggregation and coagulation. Haemostasis. 1990;20(2):99-105.

21. Epp K, Nolte H. Prolongation and normalization of bleeding time during therapy with different doses of acetylsalicylic acid [in German]. Anaesthesist. 1993;42(5):300-304.

22. Jimenez AH, Stubbs ME, Tofler GH, Winther K, Williams GH, Muller JE. Rapidity and duration of platelet suppression by enteric-coated aspirin in healthy young men. Am J Cardiol. 1992;69(3):258-262.

\section{COMMENTS}

$\mathbf{T}$ he authors present a retrospective analysis of their experience with resumption of low-dose aspirin in a population of patients who underwent burr-hole drainage of chronic subdural hematoma. They are to be commended for attempting to answer a question that so commonly comes up on rounds in the hospital. Their cohort of patients is fairly sizeable, given the specifics: only patients on low-dose aspirin undergoing surgery for chronic subdural hematoma. Unfortunately, the results really show no statistically significant differences in timing of resumption and recurrence of hematoma or even in thrombotic complications. This may actually be a desired result in that individual practitioners may feel comfortable with either holding the aspirin for a specified time for worry of recurrence or in resuming it early with the knowledge that there does not seem to be increased risk. Some important "trends" may help to guide management, specifically that early resumption (after 7 days) for patients deemed high risk for a thrombotic event was safe and that never resuming aspirin for patients having no good indication for it may decrease the risk for recurrence long term. The authors acknowledge the limitations and bias in this retrospective analysis.

Despite the lack of statistical significance, this article adds to our knowledge base and can help practitioners to develop their own protocol for resumption of aspirin. However, caution is advised in attempts to extrapolate the data in that all of these patients were on low-dose (100 mg once daily) aspirin. Conclusions cannot be applied to patients taking full-dose aspirin $(325 \mathrm{mg})$ or other doses of aspirin.

Richard B. Rodgers

Indianapolis, Indiana

$T$ his is a retrospective analysis with data that will add to our understanding and assist in guiding clinical decisions regarding this nuanced management issue.

In reviewing the recommendations, however, the strength of the article holds in focusing on stated results rather than on information that is based on extrapolated data. An unnecessary level of bias is introduced should one do the latter.

Odette Harris Stanford, California 